Pacific Northwest

National Laboratory

Operated by Battelle for the

U.S. Department of Energy

\title{
Data Analysis of Plutonium Sorption on Colloids in a Minimal Kinetics Model
}

\author{
R.S. Wittman \\ E.C. Buck \\ B.D. Hanson
}

August 2005

\footnotetext{
Prepared for the U.S. Department of Energy
} under Contract DE-AC05-76RL01830 


\title{
DISCLAIMER
}

This report was prepared as an account of work sponsored by an agency of the United States Government. Neither the United States Government nor any agency thereof, nor Battelle Memorial Institute, nor any of their employees, makes any warranty, express or implied, or assumes any legal liability or responsibility for the accuracy, completeness, or usefulness of any information, apparatus, product, or process disclosed, or represents that its use would not infringe privately owned rights. Reference herein to any specific commercial product, process, or service by trade name, trademark, manufacturer, or otherwise does not necessarily constitute or imply its endorsement, recommendation, or favoring by the United States Government or any agency thereof, or Battelle Memorial Institute. The views and opinions of authors expressed herein do not necessarily state or reflect those of the United States Government or any agency thereof.

\author{
PACIFIC NORTHWEST NATIONAL LABORATORY \\ operated by \\ BATTELLE \\ for the \\ UNITED STATES DEPARTMENT OF ENERGY \\ under Contract DE-AC05-76RL01830
}

Printed in the United States of America
Available to DOE and DOE contractors from the Office of Scientific and Technical Information,
P.O. Box 62, Oak Ridge, TN 37831-0062;
ph: (865) 576-8401
fax: (865) 576-5728
email: reports@adonis.osti.gov

\begin{abstract}
Available to the public from the National Technical Information Service, U.S. Department of Commerce, 5285 Port Royal Rd., Springfield, VA 22161 ph: (800) 553-6847 fax: (703) 605-6900 email: orders@ntis.fedworld.gov online ordering: http://www.ntis.gov/ordering.htm
\end{abstract}

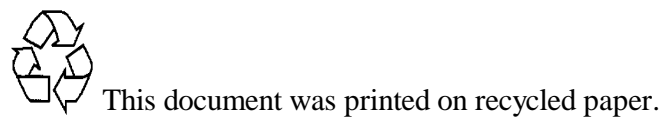


PNNL-15285

QA:NA

\title{
Data Analysis of Plutonium Sorption on Colloids in a Minimal Kinetics Model
}

\author{
R. S. Wittman \\ E. C. Buck \\ B. D. Hanson
}

August 2005

Prepared for the U.S. Department of Energy under Contract DE-AC05-76RL01830

Pacific Northwest National Laboratory

Richland, Washington 99352 


\section{Summary}

Yucca Mountain is the U.S. Department of Energy's potential geologic repository designed to store and dispose of commercial spent nuclear fuel, defense high level waste glass, and other high-level radioactive waste forms. If approved, the site would be the nation's first geological repository for disposal of this type of radioactive waste. Yucca Mountain is located on federal land adjacent to the Nevada Test Site in Nye County, Nevada. It is approximately 100 miles northwest of Las Vegas, Nevada.

Colloids may have the potential to transport strongly sorbing radionuclide contaminants in soils and groundwater aquifers (McCarthy and Zachara 1989). Recent studies from the Nevada Test Site, a site with a similar geology to Yucca Mountain, have indicated the enhanced mobility of plutonium in the saturated zone, albeit in minute quantities, in association with various silicate minerals (Kersting et al. 1999). The observed association of plutonium with silicate colloids by Kersting et al. (1999), sorption experiments by Lu et al. (2000), and waste form corrosion tests (Bates et al. 1992) indicate that the attachment of plutonium to colloids may be an irreversible process. However, current Yucca Mountain models that assume irreversible sorption of plutonium, americium, and thorium onto colloids have led to highly conservative scenarios. This is partly because of the $K_{d}$ ranges used as well as the total surface area assumed to be available for uptake. Nevertheless, a slowly reversible term may provide more realistic predictions for radionuclide transport in the proposed repository.

This report considers a sorption model containing the minimal dynamic features of the system to fit plutonium adsorption data similar to that developed by Painter et al. (2002). Global fits to recent data favored nonzero values of reversible sorption, allowing the definition of equilibrium distribution coefficients in all cases except the synthetic form of montmorillonite. In most cases, the two-site model was adequate to fit the data. The model represents a mathematic simplification of the time-dependent sorption process and takes no account for $\mathrm{pH}$-dependent surface charge changes and actinide-mineral surface interfacial chemistry. However, this allows the model to be readily incorporated into existing performance assessment codes when applied to repository environment relevant data sets.

\section{References}

Bates JK, JP Bradley, A Teetsov, CR Bradley, and M Buchholtz ten Brink. 1992. "Colloid formation during nuclear waste glass dissolution: Implications for nuclear waste disposal." Science 256:469-471.

Kersting B, DW Efund, DL Finnegan, DJ Rokop, DK Smith, and JL Thompson. 1999. "Migration of plutonium in groundwater at the Nevada Test Site." Nature 397:56-59.

Lu, N, J Conca, GA Parker, PA Leonard, B Moore, B Strietelmeier, and IR Triay. 2000. Adsorption of actinides onto colloids as a function of time, temperature, ionic strength, and colloid concentration. Technical Report LA-UR-00-5121; Los Alamos National Laboratory, Los Alamos, NM.

McCarthy JF, and JM Zachara. 1989. "Subsurface transport of contaminants." Environ. Sci. Tech. 23:496-502. 
Painter S, V Cvetkovic, D Pickett, and DR Turner. 2002. "Significance of Kinetics for Sorption of Inorganic Colloids: Modeling and Experiment Interpretation Issues." Environ. Sci. Technol, 36:5369-5375. 


\section{Glossary of Definitions and Acronyms}

$\begin{array}{ll}\text { BSC } & \text { Bechtel SAIC Company, LLC } \\ \text { CSNF } & \text { Commercial Spent Nuclear Fuel } \\ \text { DOE } & \text { U.S. Department of Energy } \\ \text { SYN } & \text { Synthetic } \\ \text { YMP } & \text { Yucca Mountain Project }\end{array}$

\section{Definitions}

Colloid

Linear isotherm
A finely divided dispersion of one material in a second continuous phase (i.e., water). Colloidal particles are generally between individual molecules and macroscopic objects. A convenient limit is that a colloid is $<1 \mu \mathrm{m}$ in at least one dimension.

The ratio of the concentration of the element adsorbed on a solid phase to that in the solution phase.

\section{Mineral Names and Formula}

Brockite

$(\mathrm{Ca}, \mathrm{Th}, \mathrm{Ce}) \mathrm{PO}_{4} \cdot \mathrm{H}_{2} \mathrm{O}$

Goethite

$\mathrm{Fe}^{3+} \mathrm{O}(\mathrm{OH})$

Hematite

$\mathrm{Fe}_{2} \mathrm{O}_{3}$

Montmorillonite

$(\mathrm{Na}, \mathrm{Ca})_{0.33}(\mathrm{Al}, \mathrm{Mg})_{2}\left(\mathrm{Si}_{4} \mathrm{O}_{10}\right)(\mathrm{OH})_{2} \bullet \mathrm{nH}_{2} \mathrm{O}$

Rhabdophane-Ce

$\mathrm{CePO}_{4} \bullet \mathrm{H}_{2} \mathrm{O}$

Silica

$\mathrm{SiO}_{2}$

Smectite

$(\mathrm{Na}, \mathrm{Ca})_{0.3}(\mathrm{Al}, \mathrm{Fe})_{2-3}(\mathrm{Si}, \mathrm{Al})_{4} \mathrm{O}_{10}(\mathrm{OH})_{2} \bullet \mathrm{nH}_{2} \mathrm{O}$

\section{Unit Abbreviations}

$\begin{array}{ll}{ }^{\circ} \mathrm{C} & \text { degrees Centigrade } \\ \mathrm{g} / \mathrm{cm}^{3} & \text { grams per cubic centimeter (density) } \\ \mathrm{L} / \mathrm{g} & \text { liters per gram } \\ \mathrm{ml} / \mathrm{g} & \text { milliliters per gram }\end{array}$





\section{Contents}

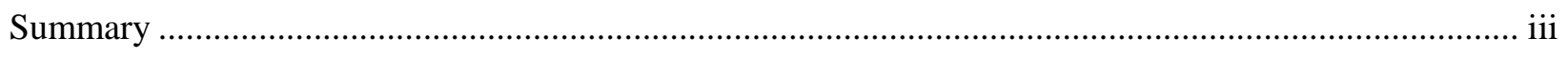

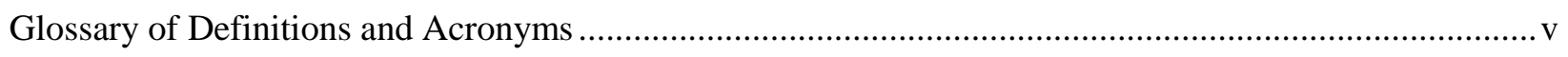

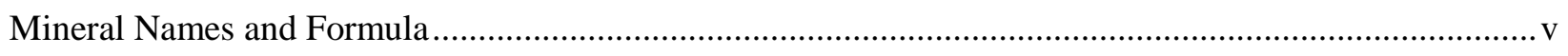

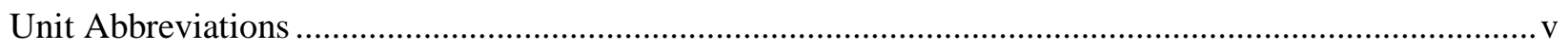

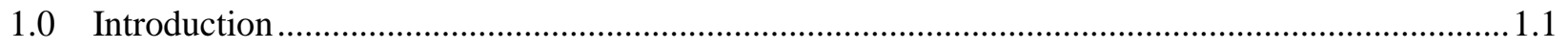

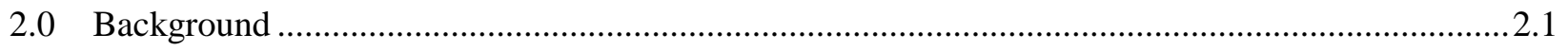

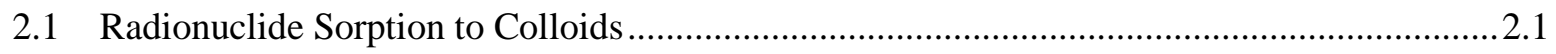

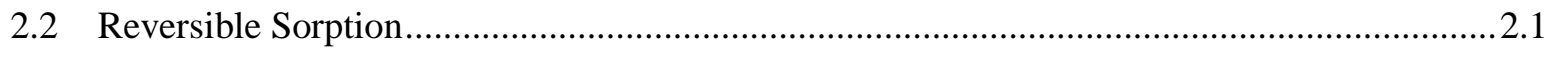

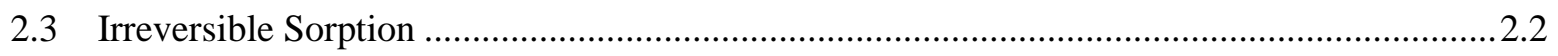

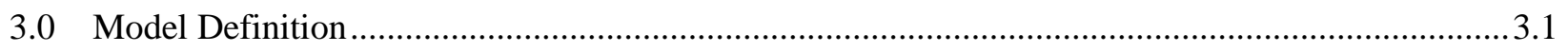

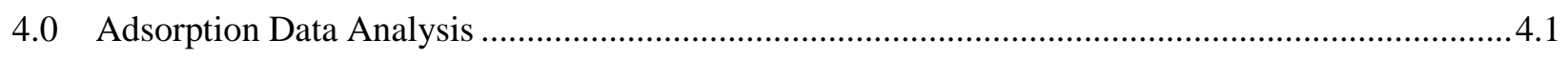

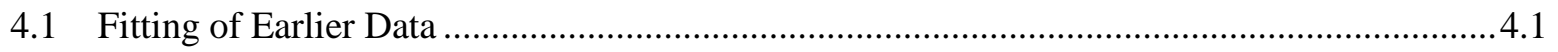

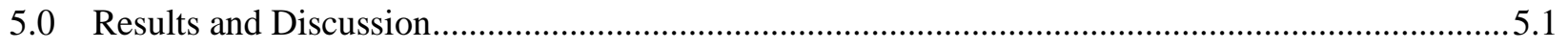

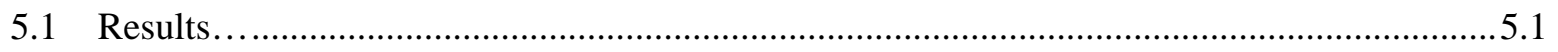

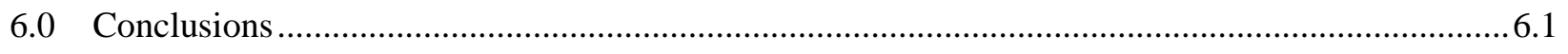

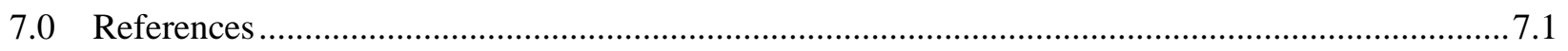




\section{Figures}

3.1. Batch or Flow-Through Reactor to Represent Batch Adsorption Data $(\omega \equiv r / V \theta=0)$ and Bulk Flow Through the Aquifer $(\omega \neq 0)$

4.1. Fraction of Plutonium Adsorbed Onto Colloids as a Function of Time Showing the Three-Site Model Fit Results

4.2. Fraction of Plutonium Adsorbed onto Colloids as a Function of Time

4.3. Three-Site Fit to Adsorption Data Resulting in Perfect Fit (solid-red) Showing Individual Site Contributions

5.1. Flow-Through Effect Of Assuming Reversible (red) vs. Irreversible (blue) Sorption

\section{Tables}

4.1. Plutonium Adsorption Fraction $C_{c} K_{d} /\left(1+C_{c} K_{d}\right)$ Inferred from Data Presented by Lu et al.

4.2. Plutonium Sorption Model Parameters.

4.3. Plutonium Adsorption Fraction for $C_{c}=1.0 \mathrm{~g} / \mathrm{L}$ from Lu et al.

5.1. Plutonium Distribution Coefficients 


\subsection{Introduction}

The U.S. Department of Energy (DOE) is planning to develop a site for long-term storage of radioactive waste products at Yucca Mountain in Nevada. Commercial Spent Nuclear Fuel (CSNF) represents the major source of radionuclides at Yucca Mountain; however, with respect to colloids, there remains uncertainty about the assumption of irreversible radionuclide sorption. With the pressing need for validation of assumptions for the transport of contaminants from a geological repository to the biosphere, it is instructive to interpret existing data with models that can extract long-term transport behavior. Performance assessment codes are limited in their capability to incorporate the role of adsorbant-mineral surface interactions with $\mathrm{pH}$ and ionic strength, microscopic sorption processes, such as the formation of inner sphere complexes and ion exchange reactions, and colloidal assisted radionuclide transport. This forces the performance assessment code to adopt relationships and conservative assumptions that may lead to unreasonable yet conservative non-physical and non-credible results. The current models either assume actinides are completely reversible or completely irreversible, whereas a more reasonable approach would be that there is a slow reversible process. More complex relationships that take account of mineral surface changes with solution conditions cannot be readily implemented into current performance assessment codes.

Irreversible sorption of plutonium and americium onto colloids has been assumed to occur based on an assessment of available data from sorption experiments (Lu et al. 1998, 2000) and waste form corrosion tests on borosilicate glass where nano-sized precipitates of plutonium bearing brockite [(Ca,Th,Ce) $\left.\mathrm{PO}_{4} \mathrm{H}_{2} \mathrm{O}\right]$ (Bates et al. 1992; Fortner et al. 1997) and plutonium-bearing rhabdophane (ideally $\mathrm{CePO}_{4} \mathrm{H}_{2} \mathrm{O}$ ) (Buck and Bates 1999) were observed closely associated with smectite clay colloids.

Kersting et al. (1999) demonstrated the occurrence of trace amounts of plutonium with colloids in the saturated zone of the Nevada Test Site that appeared to support the concept of irreversible attachment of "embedded" plutonium to carrier silicate phases. However, recent studies by Bitea et al. (2003) on precipitated thorium oxides suggested that these phases dissolved when in contact with solutions with thorium concentrations below the solubility limit for thorium hydroxide. This result suggests that the concept of irreversible embedded particles sorbed onto clays may not be reasonable. One question is whether short-term sorption experiments support a slow reversible process.

Painter et al. (2002) suggested a simple mathematical approach for predicting the sorption of radionuclides onto colloids for implementation into performance assessment codes. The model used in this work may be considered as the simplest phenomenological approach for interpreting the data and is an expansion of the ideas presented by Painter et al. (2002). Therefore, limitations can indicate the operation of more complex mechanisms or the possibility of data uncertainty. In this report, a discussion of the validity of irreversible sorption is made, and a new sorption kinetics model is defined. Sorption data are then used to assess the validity of the model and to report parameters that could apply to microscopic models. Finally, some comments are made about how the data impact the transport assumptions. 


\subsection{Background}

This section explains radionuclide sorption to non-radioactive colloids, the three critical conditions necessary for sorption, and the reversible and irreversible sorption approaches.

\subsection{Radionuclide Sorption to Colloids}

Non-radioactive colloids are only important to repository performance insofar as radionuclides sorb to them. "Sorption" as used here is a general term that is governed by 1) electrostatic forces, 2) ion exchange, 3) surface reaction, and 4) co-precipitation. Sorption may occur by a number of mechanisms and is modeled as either reversible or irreversible. The rate of sorption, desorption, and transport determine the effective reversibility of the sorption. When sorption is fast and reversible, equilibrium conditions apply, and the linear isotherm model is applicable for describing radionuclide uptake. When sorption is irreversible, or desorption is slow relative to transport times, then local equilibrium models may fail, resulting in over- or under-predictions of transport. The under-prediction of transport would occur for the case where the adsorbing media is stationary. The assumptions of irreversibility may be considered non-credible; however, such an approach is conservative and bounding, and some experimental data have suggested that this process is real.

Perhaps the most common approach used to assess contaminant-rock interactions in the subsurface is the linear isotherm, or $K_{d}$ value (distribution coefficient), approach, based on results of batch sorption experiments. The linear isotherm model relationship is defined as follows (Langmuir 1997):

$$
S=K_{d} C
$$

where $S$ is the mass of a solute adsorbed on a unit mass of solid $(\mu \mathrm{g} / \mathrm{g}), K_{d}$ is the distribution coefficient $(\mathrm{ml} / \mathrm{g})$, and $C$ is the concentration of the adsorbing solute in solution $(\mu \mathrm{g} / \mathrm{ml})$.

The amount of solute adsorbed on a solid can also be defined on the basis of area as follows:

$$
S=K_{a} C
$$

where $S$ is the mass of a solute adsorbed on a unit area of solid, $K_{a}$ is the distribution coefficient (areabased), and $C$ is the concentration of the adsorbing solute in solution.

\subsection{Reversible Sorption}

Three critical conditions must be met for the linear $K_{d}$ relationship to be applicable to colloids in the waste package environment. First, the water-radionuclide-colloid system must be in thermodynamic equilibrium (i.e., sorption must be completely reversible). Second, contaminant uptake must scale linearly with radionuclide concentration. Third, the presence of other solutes in the waste package system cannot affect the sorption. Because of the nature of the formation of waste form derived colloids and the interactions of some radionuclides, particularly some actinides, with mineral surfaces, certain conditions of the linear isotherm model are not met; therefore, other approaches may need to be taken. 
A large quantity of data exists in published literature for sorption, and, in the past several decades, increasing attention has been given to understanding the mechanisms of sorption; however, these improvements in understanding have not lent themselves to the development of models that can be used in a waste package environment. In this report, the development of $K_{d}$ values for the uptake of plutonium and americium on colloids is described, along with caveats. Values for americium have been assumed to be valid for thorium and protactinium (BSC 2004). These radionuclide elements were chosen for colloid analysis because, based on a screening exercise, they are considered by the Total Systems Performance Assessment (TSPA) to be important to dose, high uncertainty surrounds their potential behavior as pseudocolloids, and daughter products of uranium may remain associated with uranium-bearing colloids.

In this report, only plutonium has been considered for both irreversible and reversible sorption. Important isotopes with respect to dose calculations include ${ }^{239} \mathrm{Pu},{ }^{242} \mathrm{Pu}$, and ${ }^{238} \mathrm{Pu}$. Plutonium is sparingly soluble but sorbs strongly to oxide mineral surfaces (generally less strongly to silicates) (EPA 1999). The formation of pseudocolloids through the sorption of plutonium, particularly to iron oxide and oxyhydroxide colloids from corrosion of steel in a waste disposal site, may increase the effective mobility of plutonium. The chemistry of plutonium is more complex than any of the other actinides, and it can exist in the III, IV, V, and VI oxidation states with lower solubility and mobility for the lower oxidation states III and IV. The actinide elements exhibit strong hydrolysis behavior and tend to form strong carbonate complexes in the absence of other complexing ligands. The actinides may hydrolyze at $\mathrm{pH}$ values above about 6 where they are present as neutral hydroxo complexes. At slightly alkaline $\mathrm{pH}$ values and above, they will exist as negatively charged anionic hydroxyl complexes. Under disposal conditions, the presence of silicate, phosphate, and other species may alter the fate of the actinides. However, sorption is greatest in the near neutral $\mathrm{pH}$ range. Carbonate is a strong complexant, and at alkaline $\mathrm{pH}$ values, the actinides may form mono-, di-, and tri-carbonate complexes, depending on the actinide and its valence state. The presence of these complexes tends to decrease sorption. Nevertheless, a mechanistic understanding of plutonium sorption within the waste package requires detailed knowledge of the colloid environment.

\subsection{Irreversible Sorption}

Plutonium and americium have been assumed to be irreversibly attached to smectite colloids generated during the borosilicate waste glass weathering (BSC 2004) based on laboratory corrosion tests (Bates et al. 1992; Buck and Bates 1999; Fortner et al. 1997). The current model abstraction assumes that plutonium and americium are associated irreversibly within smectite colloids from the glass degradation experiments. As such, they are treated as a separate colloid subtype, and assuming that the sorbed actinides are an intrinsic part of the colloid, not in equilibrium with the aqueous system. This premise has been based on a limited set of microscopic images obtained from corrosion tests, and it is unknown whether this will occur in the repository environment. 


\subsection{Model Definition}

The features of the model discussed by Painter et al. (2002) were adopted to represent both batch and flow-through reactor conditions. The laboratory experiment (batch) and aquifer (flow-through) are represented as lumped systems. Sorption within a uniform mixture is assumed. The contaminant can be present in a mobile phase solution containing a suspended colloid and in an immobile solid phase. The contaminant in the immobile phase is assumed to be at equilibrium with that in solution whereas the contaminant in solution and on the colloid is treated dynamically. Figure 3.1 shows that water and colloid can flow into the system; water, colloid, and contaminant flow out.

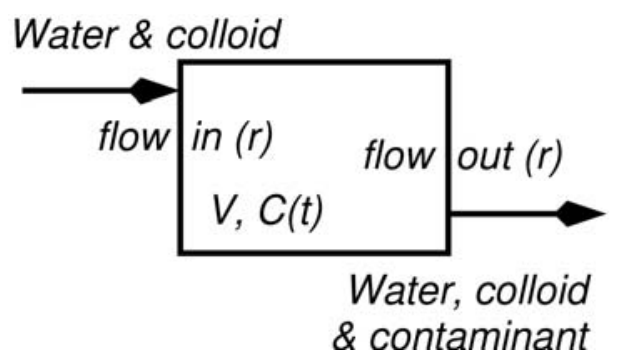

Figure 3.1. Batch or Flow-Through Reactor to Represent Batch Adsorption Data $(\omega \equiv r / V \theta=0)$ and Bulk Flow Through the Aquifer $(\omega \neq 0)$

Assuming a constant system volume $V$ such that $\dot{V} \equiv d V / d t=0$, the total mass balance for contaminant in the reactor is given by:

$$
\begin{gathered}
\frac{d}{d t}\left\{V\left[\theta C_{L}(t)+(1-\theta) \rho_{I} C_{I}(t)+\theta C_{c} C_{c p}(t)\right]\right\}= \\
-r\left[C_{L}(t)+C_{c} C_{c p}(t)\right]-\lambda V\left[\theta C_{L}(t)+(1-\theta) \rho_{I} C_{I}(t)+\theta C_{c} C_{c p}(t)\right]+Q(t)
\end{gathered}
$$

where $C_{L}(t)\left[\mathrm{ML}^{-3}\right]=$ liquid contaminant concentration

$$
\begin{aligned}
C_{c p}(t) & =\text { concentration of contaminant on the colloid particles } \\
\theta & =\text { porosity } \\
C_{c}\left[\mathrm{ML}^{-3}\right] & =\text { constant colloid concentration } \\
r\left[\mathrm{~L}^{3} \mathrm{~T}^{-1}\right] & =\text { flow-through rate } \\
\lambda\left[\mathrm{T}^{-1}\right] & =\text { contaminant decay constant } \\
\rho_{I}\left[\mathrm{ML}^{-3}\right] & =\text { density of the immobile soil. } \\
C_{I}(t) & =\text { concentration of contaminant in the soil. }
\end{aligned}
$$


Also, it was assumed that the concentration of the contaminant $C_{I}(t)$ bound to the immobile soil is fixed at equilibrium with the liquid according to $C_{I}(t)=K_{d} C_{L}(t)$, where $K_{d}$ of $5 \mathrm{~L} / \mathrm{g}$ is assumed by Painter et al. (2002). Also, it was assumed that the presence of the contaminant is accounted for in initial conditions and that the source $Q(t)$ is zero.

To account for the occurrence of various sorption process rates, the total contaminant on the colloid particles is represented as the sum of three independent contributions or sites. The interaction of each site with the liquid is given by:

$$
\frac{d}{d t}\left[C_{c p}(t)\right]_{J}=k_{F J} C_{L}(t)-\left(k_{R J}+\lambda+\frac{r}{V \theta}\right)\left[C_{c p}(t)\right]_{J}
$$

where $J$ is an index that represents independent sites or sorption processes for the colloid to interact with contaminant in the liquid. The rate constants $k_{F J}\left(\mathrm{~L}^{3} \mathrm{M}^{-1} \mathrm{~T}^{-1}\right)$ and $k_{R J}\left(\mathrm{~T}^{-1}\right)$ represent forward and reverse sorption, respectively, for the $J^{\text {th }}$ site. The independent equilibrium distribution for the $J^{\text {th }}$ site is $K_{c J}=k_{F J} / k_{R J}$

Given variables that represent the total contaminant mass contained in the liquid and the $J^{\text {th }}$ colloid site as:

$$
X_{0}(t) \equiv V \theta C_{L}(t) \text { and } \quad X_{J}(t) \equiv V \theta C_{c}\left[C_{c p}(t)\right]_{J}
$$

the rate equations take the simple form:

$$
R \dot{X}_{0}=\sum_{J} k_{R J} X_{J}-\left(C_{c} \sum_{J} k_{F J}+\lambda R+\omega\right) X_{0}
$$

and

$$
\dot{X}_{J}=C_{c} k_{F J} X_{0}-\left(k_{R J}+\lambda+\omega\right) X_{J}
$$

where the retardation factor is $R=1+(1-\theta) \rho_{I} K_{d} / \theta$, and $\omega \equiv r / V \theta$ is related to the mean residence time $\langle\tau\rangle=1 / \omega$.

Exact analytical solutions of Equations (3.4) and (3.5) were used in the analysis. Additionally, selected analytical results were independently checked with fourth order Runge-Kutta numerical solutions for consistency (Press et al. 1992). The numerical and analytical solutions were identical to the expected precision. Of course, the analytical solution offered a huge advantage in computing speed, especially for covering time ranges over several orders of magnitude. A direct way to obtain the analytical solution is by Laplace transformation of Equations (3.4) and (3.5). Assuming no initial contaminant mass on the 
colloid for the batch reactor case such that $\theta=R=1, \omega=0$ and $\lambda=0$, the Laplace transform of Equation (3.5) gives

$$
\hat{X}_{J}(s)=\frac{C_{c} k_{F J} \hat{X}_{0}(s)}{s+k_{R J}}
$$

where $\hat{X}_{0}(s)$ is given by substituting Equation (3.6) into the Laplace transform of Equation (3.4)

$$
\hat{X}_{0}(s)=\frac{1}{s\left(1+C_{c} \sum_{J} \frac{k_{F J}}{s+k_{R J}}\right)}
$$

assuming initial conditions of $X_{0}(0)=1$.

The inverse Laplace transform of Equation (3.7) is easily performed once the denominator is rationalized to a form explicitly containing the pole positions

$$
\hat{X}_{0}(s)=\frac{\left(s+k_{R 1}\right)\left(s+k_{R 2}\right)\left(s+k_{R 3}\right)}{s\left(s+s_{1}\right)\left(s+s_{2}\right)\left(s+s_{3}\right)}
$$

where $s_{1}, s_{2}$ and $s_{3}$ are obtained as minus the roots of the cubic equation

$$
s^{3}+a_{2} s^{2}+a_{1} s+a_{0}=0
$$

with coefficients defined according to

$$
\begin{gathered}
a_{2}=s_{1}+s_{2}+s_{3}=k_{R 1}+k_{R 2}+k_{R 3}+C_{c}\left(k_{F 1}+k_{F 2}+k_{F 3}\right) \\
a_{1}=s_{1} s_{2}+s_{1} s_{3}+s_{2} s_{3}=k_{R 1} k_{R 2}+k_{R 1} k_{R 3}+k_{R 2} k_{R 3} \\
+C_{c}\left(k_{F 1} k_{R 3}+k_{F 2} k_{R 3}+k_{F 1} k_{R 2}+k_{F 3} k_{R 2}+k_{F 2} k_{R 1}+k_{F 3} k_{R 1}\right)
\end{gathered}
$$

and

$$
a_{0}=s_{1} s_{2} s_{3}=k_{R 1} k_{R 2} k_{R 3}+C_{c}\left(k_{F 1} k_{R 2} k_{R 3}+k_{F 2} k_{R 1} k_{R 3}+k_{F 3} k_{R 1} k_{R 2}\right)
$$

The inverse Laplace transform of Equation (3.8) is then determined as the sum of the residues at the four simple pole positions of $s=0, s_{1}, s_{2}$ and $s_{3}$ according to

$$
\begin{gathered}
X_{0}(t)=\frac{\left(s_{1}-k_{R 1}\right)\left(s_{1}-k_{R 2}\right)\left(s_{1}-k_{R 3}\right)}{s_{1}\left(s_{2}-s_{1}\right)\left(s_{3}-s_{1}\right)} e^{-s_{1} t} \\
+\frac{\left(s_{2}-k_{R 1}\right)\left(s_{2}-k_{R 2}\right)\left(s_{2}-k_{R 3}\right)}{s_{2}\left(s_{1}-s_{2}\right)\left(s_{3}-s_{2}\right)} e^{-s_{2} t} \\
+\frac{\left(s_{3}-k_{R 1}\right)\left(s_{3}-k_{R 2}\right)\left(s_{3}-k_{R 3}\right)}{s_{3}\left(s_{1}-s_{3}\right)\left(s_{2}-s_{3}\right)} e^{-s_{3} t}+\frac{k_{R 1} k_{R 2} k_{R 3}}{s_{1} s_{2} s_{3}}
\end{gathered}
$$


Additionally, by substituting Equation (3.8) into Equation (3.6), the inverse Laplace transforms of Equation (3.6) for $J=1,2$, and 3 are obtained in the same way as expressed below:

$$
\begin{aligned}
& X_{1}(t)=-\frac{C_{c} k_{F 1}\left(s_{1}-k_{R 2}\right)\left(s_{1}-k_{R 3}\right)}{s_{1}\left(s_{2}-s_{1}\right)\left(s_{3}-s_{1}\right)} e^{-s_{1} t} \\
& -\frac{C_{c} k_{F 1}\left(s_{2}-k_{R 2}\right)\left(s_{2}-k_{R 3}\right)}{s_{2}\left(s_{1}-s_{2}\right)\left(s_{3}-s_{2}\right)} e^{-s_{2} t} \\
& -\frac{C_{c} k_{F 1}\left(s_{3}-k_{R 2}\right)\left(s_{3}-k_{R 3}\right)}{s_{3}\left(s_{1}-s_{3}\right)\left(s_{2}-s_{3}\right)} e^{-s_{3} t}+\frac{C_{c} k_{F 1} k_{R 2} k_{R 3}}{s_{1} s_{2} s_{3}} \\
& X_{2}(t)=-\frac{C_{c} k_{F 2}\left(s_{1}-k_{R 1}\right)\left(s_{1}-k_{R 3}\right)}{s_{1}\left(s_{2}-s_{1}\right)\left(s_{3}-s_{1}\right)} e^{-s_{1} t} \\
& -\frac{C_{c} k_{F 2}\left(s_{2}-k_{R 1}\right)\left(s_{2}-k_{R 3}\right)}{s_{2}\left(s_{1}-s_{2}\right)\left(s_{3}-s_{2}\right)} e^{-s_{2} t} \\
& -\frac{C_{c} k_{F 2}\left(s_{3}-k_{R 1}\right)\left(s_{3}-k_{R 3}\right)}{s_{3}\left(s_{1}-s_{3}\right)\left(s_{2}-s_{3}\right)} e^{-s_{3} t}+\frac{C_{c} k_{F 2} k_{R 1} k_{R 3}}{s_{1} s_{2} s_{3}} \\
& X_{3}(t)=-\frac{C_{c} k_{F 3}\left(s_{1}-k_{R 1}\right)\left(s_{1}-k_{R 2}\right)}{s_{1}\left(s_{2}-s_{1}\right)\left(s_{3}-s_{1}\right)} e^{-s_{1} t} \\
& -\frac{C_{c} k_{F 3}\left(s_{2}-k_{R 1}\right)\left(s_{2}-k_{R 2}\right)}{s_{2}\left(s_{1}-s_{2}\right)\left(s_{3}-s_{2}\right)} e^{-s_{2} t} \\
& -\frac{C_{c} k_{F 3}\left(s_{3}-k_{R 1}\right)\left(s_{3}-k_{R 2}\right)}{s_{3}\left(s_{1}-s_{3}\right)\left(s_{2}-s_{3}\right)} e^{-s_{3} t}+\frac{C_{c} k_{F 3} k_{R 1} k_{R 2}}{s_{1} s_{2} s_{3}}
\end{aligned}
$$

It should be mentioned that the two-site model of Painter et al. (2002) can be recovered by consistently taking $k_{F 3} k_{R 3}$, and $s_{3}$ equal to zero in Equations (3.6) to (3.16). The expression for $X_{0}(t)$ reduces to

$$
\begin{gathered}
X_{0}(t)=\frac{\left(s_{1}-k_{R 1}\right)\left(s_{1}-k_{R 2}\right)}{s_{1}\left(s_{1}-s_{2}\right)} e^{-s_{1} t} \\
+\frac{\left(s_{2}-k_{R 1}\right)\left(s_{2}-k_{R 2}\right)}{s_{2}\left(s_{2}-s_{1}\right)} e^{-s_{2} t}+\frac{k_{R 1} k_{R 2}}{s_{1} s_{2}}
\end{gathered}
$$

where now as in Painter et al. (2002), the two roots can be expressed in the simple form 


$$
s_{1}=\frac{a}{2}+b \quad \text { and } \quad s_{2}=\frac{a}{2}-b
$$

In terms of the constants $a$ and $b$ Equation (3.10) becomes

$$
a=s_{1}+s_{2}=k_{R 1}+k_{R 2}+C_{c}\left(k_{F 1}+k_{F 2}\right)
$$

and Equation (3.11) becomes

$$
\frac{a^{2}}{4}-b^{2}=s_{1} s_{2}=k_{R 1} k_{R 2}+C_{c}\left(k_{F 1} k_{R 2}+k_{F 2} k_{R 1}\right)
$$

from which the Equation (7) of Painter et al. (2002) is obtained after substituting

$$
k_{F 1}=k_{f} / C_{c}, \quad k_{R 1}=k_{r}, \quad k_{F 2}=\alpha / C_{c}, \text { and } k_{R 2}=\beta
$$

in Equations (3.17) to (3.20). The constants $a$ and $b$ are determined from

$$
a=k_{f}+k_{r}+\alpha+\beta \quad \text { and } \quad b^{2}=\frac{a^{2}}{4}-k_{r} \alpha-k_{r} \beta-k_{f} \beta
$$

It can be seen from Equation (3.22) that the last term in the expression for $b^{2}$ was missing in Painter et al. (2002). This term in general is small, but necessary for obtaining consistent equilibrium limits where the effective distribution coefficients $K_{c J}=k_{F J}{ }^{\prime} k_{R J}$ for independent sites are additive.

The time dependant expressions for a contaminant with a nonzero decay constant $\lambda$ are identical to those given, but with an overall factor of $\exp (-\lambda t)$ included for $X_{0}(t)$ and all $X_{J}(t)$. 


\subsection{Adsorption Data Analysis}

Applying the model to the data assumed conditions of a batch reactor $(\omega=0)$ with only colloid and liquid present $(R=1)$. Although there is no appreciable decay over the duration of the experiment, a small value for the decay constant $\lambda$ was assumed based on $t_{1 / 2}=24000 \mathrm{yr}$ for ${ }^{239} \mathrm{Pu}$. At $t=0$, it was assumed that all of the contaminant is present in the liquid as in the experiment ( $\mathrm{Lu}$ et al. 2000). Table 4.1 shows the adsorption data values as the fraction of plutonium adsorbed as a function of time.

Table 4.1. Plutonium Adsorption Fraction $C_{c} K_{d} /\left(1+C_{c} K_{d}\right)$ Inferred from Data Presented by Lu et al. (2000)

\begin{tabular}{|r|c|c|c|c|c|c||}
\hline \multirow{2}{*}{$\begin{array}{c}\text { Time } \\
\text { (h) }\end{array}$} & \multicolumn{2}{|c|}{ Hematite } & \multicolumn{2}{c|}{ Montmor. } & \multicolumn{2}{c||}{ Silica } \\
\cline { 2 - 7 } & $\mathbf{J - 1 3}$ & SYNJ-13 & J-13 & SYNJ-13 & J-13 & SYNJ-13 \\
\hline 1 & $0.495 \pm 0.003$ & $0.963 \pm 0.001$ & $0.044 \pm 0.004$ & $0.044 \pm 0.006$ & $0.023 \pm 0.0008$ & $0.55 \pm 0.008$ \\
\hline 4 & $0.722 \pm 0.011$ & $0.963 \pm 0.0014$ & $0.081 \pm 0.025$ & $0.046 \pm 0.011$ & $0.254 \pm 0.126$ & $0.342 \pm 0.026$ \\
\hline 24 & $0.821 \pm 0.013$ & $0.968 \pm 0.004$ & $0.141 \pm 0.012$ & $0.180 \pm 0.04$ & $0.524 \pm 0.0045$ & $0.664 \pm 0.011$ \\
\hline 48 & $0.938 \pm 0.006$ & $0.971 \pm 0.0$ & $0.167 \pm 0.0042$ & $0.194 \pm 0.0013$ & $0.537 \pm 0.0086$ & $0.664 \pm 0.011$ \\
\hline 96 & $0.951 \pm 0.008$ & $0.993 \pm 0.0$ & $0.444 \pm 0.044$ & $0.254 \pm 0.011$ & $0.573 \pm 0.0011$ & $0.706 \pm 0.0007$ \\
\hline 240 & $0.957 \pm 0.001$ & $0.960 \pm 0.01$ & $0.537 \pm 0.048$ & $0.565 \pm 0.095$ & $0.618 \pm 0.0003$ & $0.750 \pm 0.082$ \\
\hline
\end{tabular}

\subsection{Fitting of Earlier Data}

Best fits to the data were obtained by performing a least squares fit for the six rate constants of Equations (3.4) and (3.5). A multidimensional secant method (Broyden's method [Press et al. 1992]) was used to search for a local least squares fit with resulting rate constants shown in Table 4.2. Of course, there was no guarantee that a unique global minimum was determined. The results of the fits compared with the data are shown in Figures 4.1 and 4.2.

Figure 4.1 presents fits to data from Lu et al. (2000). The curves represent the best fits to the adsorption data on natural (solid) and synthetic (dashed-dot) forms of the minerals. Two separate fits were performed for the synthetic form of silica because no model parameters were found that could account for the desorption indicated at the 4-h point. The dashed curve fit omits the 4-h silica-SYN point; the corresponding dashed-dot curve omits the 1-h silica-SYN point. A reversible rate constant was obtained for the dashed-dot curve, but not for the dashed curve; therefore, the fit results for this mineral should be considered inconclusive. For the natural silica, no similar problem was encountered, and a consistent fit was possible, although a larger than usual error was present for the 4-h data point. The data for the natural and synthetic montmorillonite appeared to followed a similar trend, although the fit to the synthetic form of montmorillonite (montmorillonite-SYN), (Figure 4.1 [dashed-dot curve]) did not indicate a reversible rate constant needed to define a distribution coefficient. The difference between the two fits primarily depended on the 96-h data points. Global fits for all other cases indicated a nonzero reversible rate constant, although considerations of Painter et al. (2002) suggest that a $k_{R J}<0.001 \mathrm{~h}^{-1}$ is not resolvable for $\mathrm{t}<240 \mathrm{~h}$ within an error margin of $1 \%$. It is interesting that global fits to hematite data 
could account for relatively large forward rate constants while still favoring nonzero reversible rate constants.

Table 4.2. Plutonium Sorption Model Parameters

\begin{tabular}{|c|c|c|c|c|c|c|c|}
\hline \multirow[b]{2}{*}{ Mineral } & \multirow[b]{2}{*}{$C_{c}(\mathrm{~g} / \mathrm{L})$} & \multicolumn{6}{|c|}{ Rate Constants $\left(\mathrm{h}^{-1}\right)$} \\
\hline & & $C_{c} k_{F 1}$ & $k_{R 1}$ & $C_{c} k_{F 2}$ & $k_{R 2}$ & $C_{c} k_{F 3}$ & $k_{R 3}$ \\
\hline Silica & 0.2 & 0.07586 & 0.07058 & 0.00201 & 0.0003601 & 0.0 & 0.0 \\
\hline Silica-SYN & 0.2 & 0.1159 & 0.06586 & 0.004992 & 0.0015065 & 0.0 & 0.0 \\
\hline Silica-SYN(dshd) & 0.2 & 1.205 & 0.650 & 0.00412 & 0.0 & 0.0 & 0.0 \\
\hline Hematite & 0.2 & 0.7636 & 0.4169 & 0.0956 & 0.00384 & 0.0 & 0.0 \\
\hline Hematite-SYN & 0.2 & 18.494 & 1.3916 & 6.1461 & 0.2903 & 0.0 & 0.0 \\
\hline Montmor. & 0.2 & 0.3885 & 9.6486 & 0.005627 & 0.003535 & 0.0 & 0.0 \\
\hline Montmor-SYN & 0.2 & 0.0714 & 1.181 & 0.00342 & 0.0 & 0.0 & 0.0 \\
\hline Smectite & 1.0 & 2.0845 & 1.9933 & 0.1334 & 0.04747 & 0.01787 & 0.00171 \\
\hline Silica & 1.0 & 0.2881 & 0.7053 & 0.00743 & 0.0038 & 0.0 & 0.0 \\
\hline
\end{tabular}

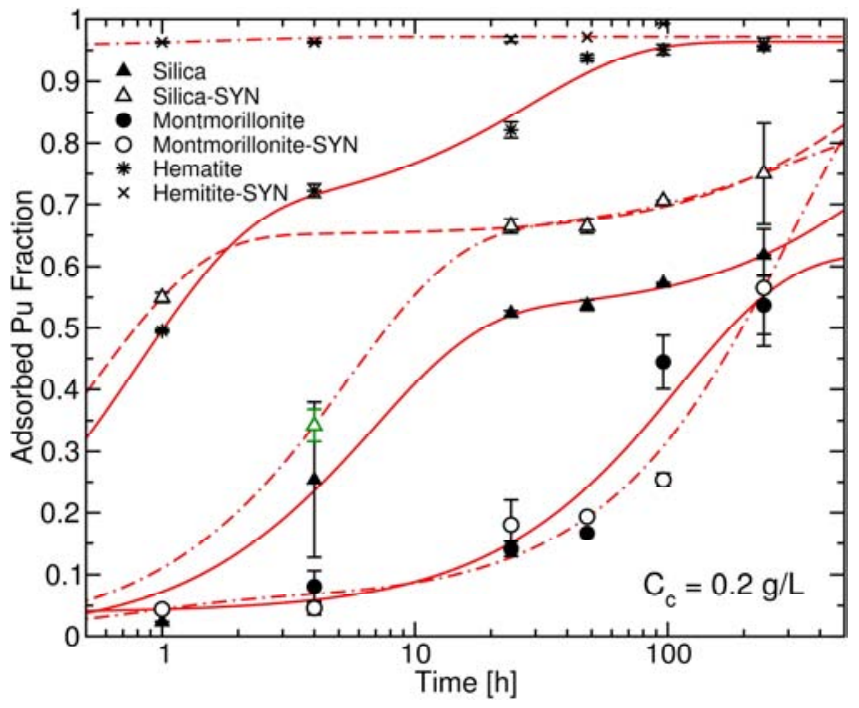

Figure 4.1. Fraction of Plutonium Adsorbed Onto Colloids as a Function of Time Showing the Three-Site Model Fit Results

Figure 4.2 shows fits to data from Lu et al. (1998) at higher colloid concentration. The solid curves describe a three-site model fit. The dashed curves use the two-site parameters from a two step fitting approach described Painter et al. (2002). 


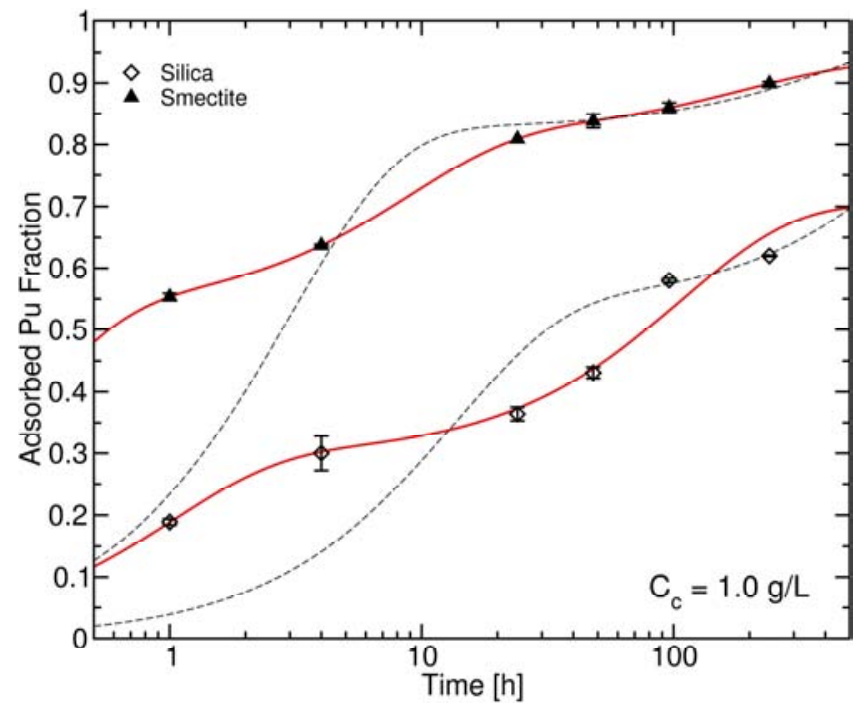

Figure 4.2. Fraction of Plutonium Adsorbed onto Colloids as a Function of Time. Solid curves are global fits to data, and dashed curves result from a two step fitting approach of Painter et al. (2002)

The two-step approach relied on an asymptotic solution and was sufficient for the conclusions of Painter et al. (2002). For the present application, it was found that the least squares approach was more reliable for a quantitative fit to the full data set.

Table 4.3 shows the adsorption data values as the fraction of plutonium adsorbed as a function of time for $C_{c}=1.0 \mathrm{~g} / \mathrm{L}$.

Table 4.3. Plutonium Adsorption Fraction for $C_{c}=1.0 \mathrm{~g} / \mathrm{L}$ from $\mathrm{Lu}$ et al. (1998)

\begin{tabular}{|r|c|c|}
\hline Time (h) & Smectite & Silica \\
\hline 1 & $0.553 \pm 0.006$ & $0.189 \pm 0.005$ \\
\hline 4 & $0.637 \pm 0.002$ & $0.3 \pm 0.028$ \\
\hline 24 & $0.809 \pm 0.0$ & $0.364 \pm 0.011$ \\
\hline 48 & $0.838 \pm 0.011$ & $0.431 \pm 0.009$ \\
\hline 96 & $0.86 \pm 0.008$ & $0.58 \pm 0.003$ \\
\hline 240 & $0.899 \pm 0.003$ & $0.62 \pm 0.001$ \\
\hline
\end{tabular}

Table 4.2 gives the values of all rate constants resulting from the fits. It should be noted that even though six parameters were adjusted, a fairy restrictive effect on the shape of the adsorption curves was possible. It was not known from the outset if a third site would be required to fit adsorption data. In most cases, the constants associated with the third site were unable to improve the fit and resulted in zero values.

A notable exception was adsorption onto smectite at $C_{c}=1.0 \mathrm{~g} / \mathrm{L}$. In this case, the six parameters resulted in a near perfect fit (Figure 4.3). Figure 4.3 shows the time dependence of both the total colloid adsorption and the individual site contributions. For the current fits, the rate constants are taken as empirical parameters to account for independent processes occurring at various rates. It has not been 
determined if the parameters selected for the third site are representative of an underlying sorption process or the limitation in the sorption data. Ideally, it would be desirable to identify a physical process associated with each distinct contribution to more generally predict how rate constants and sorption behavior would change under various conditions of $\mathrm{pH}$ and temperature. The results of few-site models might serve as a necessary first step in understanding those processes.

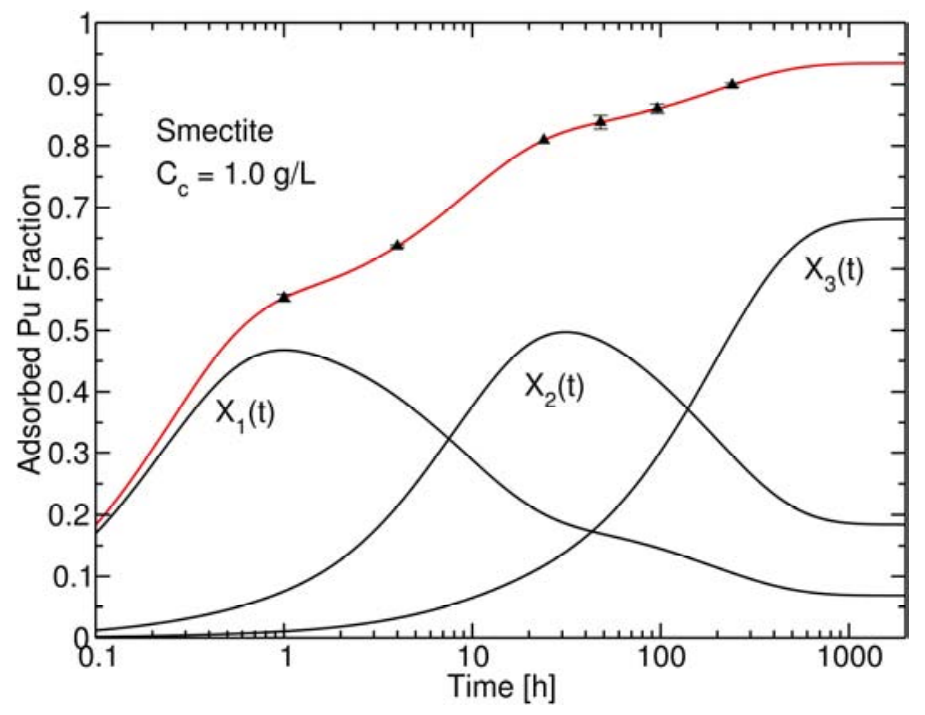

Figure 4.3. Three-Site Fit to Adsorption Data Resulting in Perfect Fit (solid-red) Showing Individual Site Contributions 


\subsection{Results and Discussion}

\subsection{Results}

The rate constants of Table 4.2 can be used to calculate effective distribution coefficients for the colloid. Table 5.1 reports the values defined at equilibrium according to $C_{c p}(t)=K_{c} C_{L}(t)$. The effective distribution coefficients are taken as the sum of their site-specific values. This is consistent with their additivity within the model.

Table 5.1. Plutonium Distribution Coefficients

\begin{tabular}{|c|c|c|c|c|c|}
\hline \multirow[b]{2}{*}{ Mineral } & \multirow[b]{2}{*}{$C_{c}(\mathrm{~g} / \mathrm{L})$} & \multicolumn{4}{|c|}{$K_{c}(\mathbf{L} / \mathrm{g})$} \\
\hline & & $K_{c 1}$ & $K_{c 2}$ & $K_{c 3}$ & $K_{c}($ Total $)$ \\
\hline Silica & 0.2 & 5.37 & 27.9 & - & 33.3 \\
\hline Silica-SYN & 0.2 & 8.80 & 16.6 & - & 25.4 \\
\hline Silica-SYN(dshd) & 0.2 & 9.27 & $\infty$ & - & $\infty$ \\
\hline Hematite & 0.2 & 9.16 & 124.5 & - & 133.6 \\
\hline Hematite-SYN & 0.2 & 66.4 & 105.9 & - & 172.3 \\
\hline Montmor. & 0.2 & 0.20 & 7.96 & - & 8.16 \\
\hline Montmor-SYN & 0.2 & 0.30 & $\infty$ & - & $\infty$ \\
\hline Smectite & 1.0 & 1.046 & 2.81 & 10.4 & 14.3 \\
\hline Silica & 1.0 & 0.408 & 1.96 & - & 2.36 \\
\hline
\end{tabular}

Painter et al. (2002) demonstrated a simple way to gage the impact of reversible rate constants. A qualitative behavior of the aquifer can be represented as a flow-through reactor $(\omega \neq 0)$. Figure 5.1 shows the long-term presence of mobile contaminant in a system as a function of time for smectite, assuming a mean flow-through residence time $\langle\tau\rangle$ of 4000 years. At $t=0$, the contaminant is assumed to be entirely distributed between the liquid and the immobile soil. In the case of irreversible flow, adsorption onto the colloid continues to increase the mobile fraction of the contaminant until the "source" contribution from the immobile soil and liquid drops to low concentrations from dilution. For reversible flow, adsorption onto the colloid reaches an equilibrium maximum long before dilution effects purge the contaminant from the system - a greater fraction remains in the immobile phase during most of the flow history. 


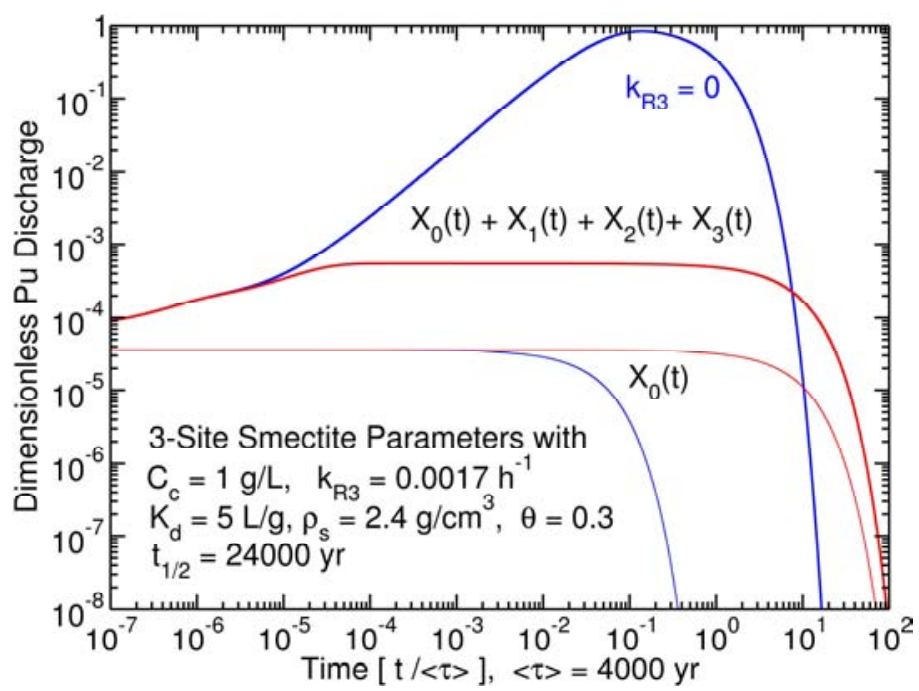

Figure 5.1. Flow-Through Effect Of Assuming Reversible (red) vs. Irreversible (blue) Sorption

The irreversible case of Figure 5.1 assumes that the slowest reversible rate constant $k_{R 3}$ is zero; in the reversible case, $k_{R 3}$ is assumed to be the value $\left(0.0017 \mathrm{~h}^{-1}\right)$ obtained from fitting the smectite data. Even though the total mobile concentration would possibly be low in both reversible and irreversible cases, the peak concentration for the reversible case is about 1000 times lower. Additionally, in the reversible case, the equilibrium behavior over most of the flow history supports the use of a distribution coefficient for representing sorption in colloid-assisted transport models. 


\subsection{Conclusions}

The sorption kinetic model allows interpretation of short-term sorption data from laboratory tests and provides a useful method for incorporating time-dependent sorption parameters into the present models for the proposed repository. Global fits to earlier data favored nonzero values of reversible sorption allowing the definition of equilibrium distribution coefficients in all cases except the synthetic form of montmorillonite. The largest (finite) distribution coefficients of about $150 \mathrm{~L} / \mathrm{g}$ were seen for hematite. Additionally, the fits to the sorption data for the synthetic form of silica could not conclusively determine a consistent set of rate constants. It is not known if the problem resulted from a limitation of the model or from the data. In most cases, the two-site model was adequate to fit the data. The smectite data were unique in that the six rate constants of the three-site model could be adjusted to give a perfect fit. 


\subsection{References}

Bates JK, JP Bradley, A Teetsov, CR Bradley, and M Buchholtz ten Brink. 1992. "Colloid formation during nuclear waste glass dissolution: Implications for nuclear waste disposal." Science 256:469-471.

Bechtel SAIC Company, LLC (BSC). 2004. Waste Form and In-drift Colloids-Associated Radionuclide Concentrations: Abstraction and Summary. MDL-EBS-PA-000004 REV 01, Civilian Radioactive Waste Management (CRWMS) Management and Operations (M\&O), Las Vegas, NV.

Bitea C, R Müller, V Neck, C Walther, and JI Kim. 2003. "Study of the Generation and Stability of Thorium(IV) Colloids by LIBD Combined with Ultrafiltration." Colloids and Surfaces A: Physicochemical and Engineering Aspects 217, 63-70.

Buck EC, and JK Bates. 1999. "Microanalysis of colloids and suspended particles from nuclear waste glass alteration." Appl. Geochem. 14:635-653.

Fortner JA, JK Bates, and TJ Gerding. 1997. Analysis of Components from Drip Tests with ATM-10 Glass. ANL-96/16, Argonne National Laboratory, Argonne, IL.

Kersting B, DW Efund, DL Finnegan, DJ Rokop, DK Smith, and JL Thompson. 1999. "Migration of plutonium in groundwater at the Nevada Test Site." Nature 397:56-59.

Langmuir D. 1997. Aqueous Environmental Geochemistry. Prentice Hall, Upper Saddle River, NJ.

Lu N, J Conca, GA Parker, PA Leonard, B Moore, B Strietelmeier, and IR Triay. 2000. Adsorption of actinides onto colloids as a function of time, temperature, ionic strength, and colloid concentration. Technical Report LA-UR-00-5121, Los Alamos National Laboratory. Los Alamos, NM.

Lu N, IR Triay, CR Cotter, HD Kitten, and J Bentley. 1998. Reversibility of sorption of Plutonium-239 onto colloids of Hematite, Goethite, Smectite and Silica: A milestone final report of YMP. Technical Report LA-UR-98-3057, Los Alamos National Laboratory, Los Alamos, NM.

Painter S, V Cvetkovic, D Pickett, and DR Turner. 2002 "Significance of Kinetics for Sorption of Inorganic Colloids: Modeling and Experiment Interpretation Issues." Environ. Sci. Technol. 36:5369-5375.

Press WH, BP Flannery, SA Teukolsky, and WT Vetterling. 1992. Numerical Recipes in FORTRAN: The Art of Scientific Computing, 2nd ed. Cambridge University Press, Cambridge, England.

U.S. Environmental Protection Agency (EPA). 1999. Understanding Variation in Partition Coefficient, $K d$, Values. EPA 402-R-99-004A\&B, Two volumes, Washington, D.C. 


\section{Distribution}

No. of

Copies

OFFSITE

9 Bechtel SAIC Company, LLC 1180 Town Center Drive

Las Vegas, NV 89144

Attn: Dennis Thomas (2)

Ernest Hardin (2)

William Duffy

Patricia Bernot

Emma Thomas

David Stahl

Christine Stockman

2 Argonne National Laboratory

9700 South Cass Avenue

Argonne, IL 60439

$\begin{array}{ll}\text { Attn: } & \text { Carol J Mertz } \\ & \text { James C Cunnane }\end{array}$

2 Sandia National Laboratory

1515 Eubank SE

Albuquerque, NM 87123

Attn: Patrick V Brady

Charles Bryan
No. of

Copies

ONSITE

21 Pacific Northwest National Laboratory

RS Wittman (6)

BD Hanson (10) P7-27

EC Buck

P7-27

M Douglas

P7-22

J Abrefah

P7-27

Technical Report Files (2)

Distr. 1 